\title{
Traces of fatigue in an attention dual task: II
}

\author{
E. SOETENS, M. DEBOECK, and J. HUETING \\ University of Brussels, Brussels, Belgium
}

\begin{abstract}
Effects of physical effort have been difficult to trace in attention tasks for various reasons, such as the activating effect of the laboratory situation or the spare capacity in automated tasks. Instead, Vervaeck, Deboeck, Hueting, and Soetens (1982) proposed a dual task, reflecting quantitatively the changes that take place in the processing of information when fatigue is introduced. This is a follow-up paper with a similar method; that is, a visual-auditory dual task is presented $30 \mathrm{~min}$ after physical effort. The results revealed that the deterioration of performance in the more difficult part of the visual component of the task, found in the previous study, was not due to an increased distraction of fatigued subjects, but rather to a shortage of allocatable capacity. It is suggested that parallel processing occurs with one fast processing line, which is used for evaluating the requirements of the task. Combining this information with an estimation of the available allocatable capacity, subjects decide to continue or to interrupt the processing of the stimulus.
\end{abstract}

It is generally accepted that people tend to make wrong decisions when they are physically tired. On the other hand, "jogging" or a long walk in the morning are said to stimulate mental work during the rest of the day. How can these ideas be reconciled?

Davey (1973) conducted an experiment that could possibly give the answer to this question. Five groups of subjects had to practice on a bicycle ergometer, going from light practice for Group 1 to intensive practice for Group 5. Before and after practice, subjects were asked to perform a mental task. In the light- and intensivepractice groups, performance on the mental task deteriorated. In the middle group, on the contrary, performance ameliorated. Possibly, the jogger can be compared to the subjects in Davey's middle group, whereas tired people making wrong decisions can be compared to the subjects in the intensive-practice condition. However, we must be careful in interpreting Davey's results. His subjects had to perform the mental task immediately after physical exercise. It is clear that physiological factors, such as respiration and sweat secretion, can have a disturbing influence on the execution of the mental task, especially for the subjects in the intensive-practice condition.

In contrast to Davey (1973), most researchers have not found any influence of different levels of physical load on problem solving or simple reaction time tasks (e.g., Blitz, 1976; Näätänen, 1975). Nevertheless, some of the conditions in these experiments can certainly be compared to those for Davey's intensive-practice group. Subjects seem to be able to compensate fatigue in some conditions, by allocating more effort to the task at hand. Such conflicting results in fatigue studies are difficult to explain.

Requests for reprints should be sent to Eric Soetens, Laboratory of Experimental Psychology, Waverse steenweg 1077, B-1160 Brussels, Belgium.
Some attribute it to an increased activation induced by the artificial laboratory situation, whereas others suggest that the demands of the task elicit different degrees of boredom. In general, human flexibility is the main cause for the disparity in the results. Many theorists have been confronted with this flexibility problem. In this context, capacity models have been developed. In these models (e.g., Kahneman, 1973), it is assumed that the processing system of each individual has a limited capacity, which can be allocated to different processing stages in a flexible way. Kahneman's (1973) capacity model for example, suggests that fatigue can be compensated by turning on more resources or capacity to perform the task at hand. This results in a reduction in subjects' spare capacity. If this theory is correct, it might be rewarding to find a way to measure this spare capacity. For this purpose, several researchers have employed the dual-task method (e.g., Brown, 1967).

Vervaeck, Deboeck, Hueting, and Soetens (1982) remarked that selection of a dual task has to be made very carefully. In their experiment, they opted for a nontypical laboratory situation. As mentioned before, in laboratory experiments subjects can be raised to an artificial level of activation, creating an important increase in the subjects' available capacity. In Vervaeck et al.'s experiment, fatigue was introduced by letting the subjects perform a paced physical task at nearly maximum level. Thereupon, an attention dual task, in which both selective and intensive aspects of attention were taken into account, was presented. An interesting aspect of the attention task was that the subjects performed at an easy, far-belowmaximum, pace. In this way, subjects could decide what component of the task to reproduce.

The task consisted of an auditory and a visual component. The auditory component was a binary-choice task. The visual component was a classical span-of-attention task, in which 3 to 12 dots were presented on a white sur- 
face. Subjects were instructed to answer with a zero if they were not able to respond to the presented stimulus. Vervaeck et al. found an influence of physical effort only in these zero responses to complex visual stimuli. Their results were in agreement with Kahneman's (1973) variable allocation capacity model. This model implies that physical effort reduces the available capacity. In these circumstances, "effort demanding" activities are first to fail.

However, in the dot task used by Vervaeck et al. (1982), there were two reasons why subjects made zero responses. (1) It is possible that subjects did not see the presented stimulus. Subjects could have been distracted by accidental external circumstances, and possibly more so when physically tired. (2) More interesting in connection with Kahneman's (1973) capacity model are zero responses for which subjects actually saw the presented stimulus, but were not able or did not want to make an estimation. It was decided to conduct a follow-up experiment in which both phenomena could be separated. Subjects were instructed to note a zero only if they did not see the stimulus. If they saw the stimulus, but were not able to estimate the number of dots, they were instructed to write down a question mark. It is predicted that tired subjects will more often respond with question marks to complex stimuli than will untired subjects. In other words, when the number of dots is large, subjects will not be able to make an estimation when fatigue has limited their allocatable capacity. It is also predicted that the number of zero responses will not change with the level of fatigue and that it is also independent of the number of dots.

\section{METHOD}

\section{Subjects}

Thirty male subjects, between 18 and 21 years of age, participated in the experiment.

\section{Physical Task}

The subjects performed the Cooper test: a 12-min run, covering as great a distance as possible. Thereupon, after a 5-min rest period, they had to perform five speed tests over $200 \mathrm{~m}$. Each test had to be run in less than $30 \mathrm{sec}$. The average heart rate between running tests was about 150 beats per minute.

\section{Attention Dual Task and Procedure}

Unless otherwise mentioned, the task was identical to the one in the study by Vervaeck et al. (1982). Two counterbalanced groups of subjects were told that the number of tachistoscopically presented dots was a minimum of 3 and a maximum of 12 . A third, control group, executing the task twice without physical effort, was added. The most important change concerned the zero responses. The subjects were instructed to write only zero responses when the stimulus projection was not seen. If they did see the stimulus, but the number of dots could not be estimated, a question mark was to be noted.

\section{RESULTS AND DISCUSSION}

As in the previous study (Vervaeck et al., 1982), no effect of fatigue was found between the total scores of the dual task with and without physical effort. The only significant difference between the conditions can be found in the zero and question-mark responses to the visual com- ponent of the task. In Figure 1, zero and question-mark responses are displayed as a function of number of dots for subjects with and without physical effort. Figure 1, panel a, shows zero responses, whereas Figure 1, panel $b$, shows question-mark responses.

Figure 1 demonstrates clearly that the influence of fatigue is present only in the question-mark responses (Wilcoxon, $\mathrm{p}<.01)$. Moreover, the influence appears only for the larger number of dots. There is no influence of fatigue in the zero responses. It can thus be concluded that the subjects were not more distracted when tired.

How can it be explained that, after physical effort, subjects write down more question marks only in response to complex visual stimuli. It is apparent that some of the stimulus information has been processed. The results suggest that subjects process some global impression of the information very quickly, which gives them a rough idea about the quantity of dots. In this way, they are able to estimate the effort required to process the complete stimulus-response cycle. Combining this information with an evaluation of the supply of attention, the subjects then decide whether to continue or to stop the processing. This idea implies parallel processing with one fast processing line in which stimuli are roughly categorized. Vervaeck et al. (1982) remarked that such a feedback system can be thought of as working along the same line as the per-
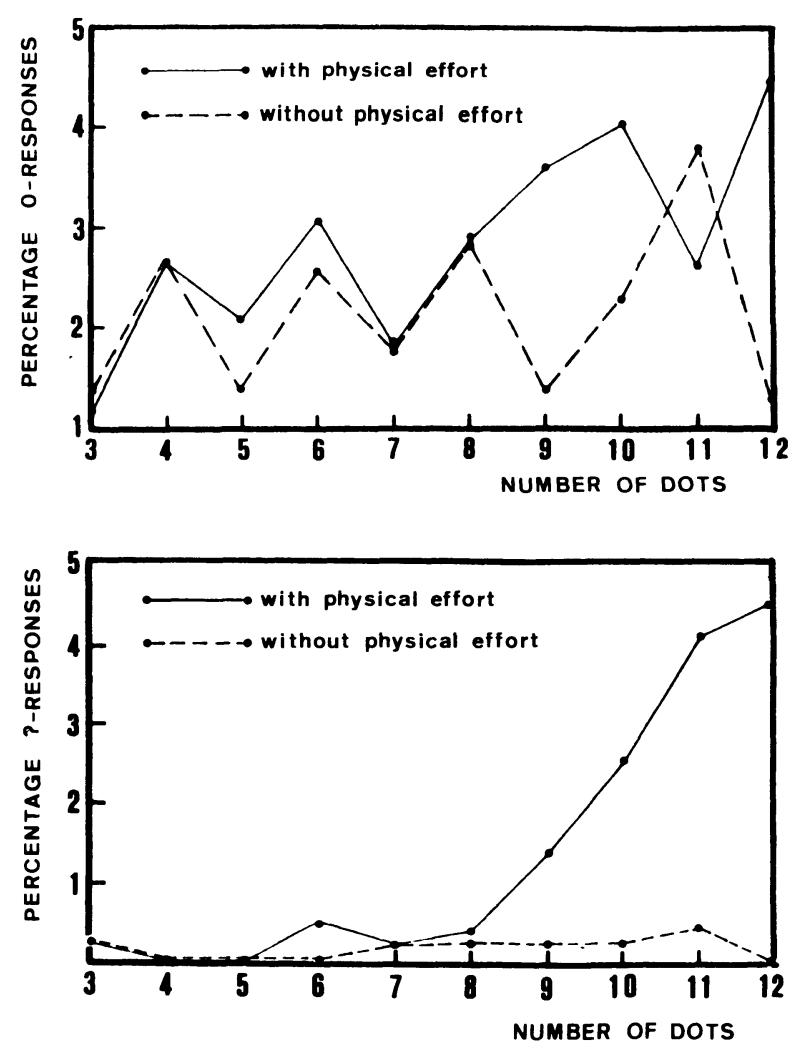

Figure 1. Zero and question-mark responses as a function of number of dots for subjects with and without physical effort. Panel a captures zero responses; panel b captures question-mark responses. 
ception of meaningful levels, before subjects are aware of the analysis (Craik \& Lockhart, 1972; Marcel, 1980).

The second processing line is much slower and can be described in terms of a structural processing system. Klahr (1973) observed that different processes seem to be involved for counting up to six dots or more. The term "subitizing" is used for numbers smaller than six and is described as a self-terminating scan of short-term memory for a match between the encoded stimulus and a short list of quantitative symbols. For larger numbers, the dots have to be counted, which is a more complex process, requiring more resources. This difference in processing mechanisms can explain the fact that, in the present experiment, the influence of fatigue is observed only with larger numbers of dots. Fatigued subjects, realizing that the allocatable attention capacity is not sufficient, can decide to interrupt the counting process.

In general, the results of the present experiment are in agreement with the study of Vervaeck et al. (1982) and support the theory proposed in their paper. The dual-task method, given appropriate test conditions, provides a measure of the influence of fatigue. It also shows how fatigue can interfere with the human processing system, in spite of its flexibility.

\section{REFERENCES}

BLITZ, P. S. (1976). Vermoeidheid: Doorgaan of afstappen? [Fatigue: Go ahead or step aside?]. In J. E. Hueting \& R. A. Blinkhorst (Eds.), Sport, lichamelijke vorming en wetenschap (pp. 67-80). Leiden: Meander.

Brown, I. D. (1967). Car driving and fatigue. Triangle, 8, 131-137. CraIK, F. I., \& LockHART, R. S. (1972). Levels of processing: A framework for memory research. Journal of Verbal Learning and Verbal Behaviour, 11, 671-684.

Davey, C. P. (1973). Physical exertion and mental performance. Ergonomics, 16, 5.

Kahneman, D. (1973). Attention and effort. Englewood Cliffs, NJ: Prentice-Hall.

KLAHR, D. (1973). Quantification processes. In W. G. Chase (Ed.), Visual information processing (pp. 3-34, 527-546). New York: Academic Press.

MARCEL, T. (1980). Concious and preconcious recognition of polysemous words: Locating the selective effects of prior verbal context. In R. S. Nickerson (Ed.), Attention and performance VIII (pp. 435457). Hillsdale, NJ: Erlbaum.

NääTäNEN, R. (1975). Selective attention and evoked potentials in humans: A critical review. Biological Psychology, 2, 237-307.

Vervaeck, K., Debeock, M., Hueting, J., \& Soetens, E. (1982). Traces of fatigue in an attention dual task. Bulletin of the Psychonomic Society, 19, 151-154.

(Manuscript received for publication June 13, 1984.) 